\title{
Muerte digna. Lugar constitucional y núcleo esencial de un derecho humano emergente
}

\author{
Recibido: 15 de abril de 2020 • Aprobado: 25 de mayo de 2020 \\ https://doi.org/10.22395/ojum.v20n4la4
}

Lucas Correa-Montoya

Universidad de los Andes,

Laboratorio de Derechos Económicos, Sociales y Culturales (DescLAB)

Bogotá, Colombia

Icorrea@desclab.com

https://orcid.org/0000-0002-4155-9885

\section{RESUMEN}

A partir de una investigación jurídica que versó principalmente sobre la jurisprudencia de la Corte Constitucional colombiana en un periodo de más de veintisiete años, el artículo aborda la pregunta por el lugar constitucional que ocupa el derecho emergente a morir dignamente en el contexto constitucional colombiano. Para ello, analiza los avances de su consolidación como derecho autónomo, presenta los contornos de su núcleo esencial reconocido por la jurisprudencia, así como sus relaciones y tensiones con otros derechos constitucionales.

Palabras clave: derechos humanos emergentes; derecho a morir dignamente; activismo judicial; eutanasia. 


\section{Death with Dignity. Constitutional Place and Essential Core of an Emerging Human Right}

\section{ABSTRACT}

Via the analysis of the decisions of the Colombian Constitutional Court in a period of 27 years, this paper addresses the question of the place of the emerging right to die with dignity in the Colombian constitutional context. To do this, it analyzes its consolidation as a full-fledge constitutional right, presents the contours of its core and the relations and tensions with other constitutional rights.

Keywords: emerging human rights, right to die with dignity, judicial activism, euthanasia

\section{Morte com dignidade. Lugar constitucional e núcleo essencial de um direito humano emergente.}

\section{RESUMO}

Baseado em pesquisas jurídicas que se concentraram principalmente na jurisprudência do Tribunal Constitucional colombiano durante um período de mais de vinte e sete anos, este artigo aborda a questão do lugar constitucional do direito emergente de morrer com dignidade no contexto constitucional colombiano. Para isso, analisa o progresso de sua consolidação como direito autônomo, apresenta os contornos de seu núcleo essencial reconhecido pela jurisprudência, bem como suas relações e tensões com outros direitos constitucionais.

Palavras-chave: direitos humanos emergentes; direito a morrer com dignidade; ativismo judicial; eutanásia. 


\section{INTRODUCCIÓN}

Este texto presenta los hallazgos de una investigación llevada a cabo por DescLAB en torno al proceso de emergencia y consolidación del derecho a morir dignamente en Colombia a través del activismo judicial como catalizador del cambio social y normativo. Presenta, a partir de un proceso de investigación jurídica, el análisis sobre la forma en que este derecho emergente se ha posicionado a lo largo del contínuum de derechos humanos garantizados por la Constitución Política de Colombia y reconocidos en tratados internacionales. Además, detalla el contenido mínimo que ha logrado en ese proceso de emergencia.

El artículo se compone de tres secciones. En la primera sección se aborda de manera sucinta el concepto de derechos emergentes y se relaciona con algunos reconocimientos internacionales parciales del derecho a morir dignamente, así como su naturaleza constitucional. En la segunda sección se describen y analizan las relaciones y tensiones del derecho a la muerte digna con otros derechos constitucionales. Se aborda, igualmente, la manera en que la Corte Constitucional colombiana, en su ejercicio de creación de derecho, ha posicionado este derecho emergente en el contínuum de derechos constitucional e internacionalmente protegidos. La tercera sección aborda el núcleo esencial del derecho a morir dignamente, los requisitos que deben cumplirse para acceder a él y las distintas vías a través de las cuales puede materializarse. Al final se presentan algunas conclusiones sobre el proceso de emergencia del derecho.

\section{DERECHOS HUMANOS EMERGENTES Y LA NATURALEZA DEL DERECHO A MORIR DIGNAMENTE}

El derecho a morir dignamente, como ha emergido en el ordenamiento constitucional colombiano, brinda la posibilidad a las personas de que el fin de su vida tenga lugar en condiciones de dignidad, libre de dolor y sufrimientos, en el que se respete su autonomía, decisiones y el libre desarrollo de su personalidad. El derecho a morir dignamente puede materializarse a través de tres vías relacionadas y que no se excluyen entre sí: el acceso a cuidados paliativos, la eutanasia pasiva, es decir, la posibilidad de negarse, interrumpir o prescindir de procedimientos y tratamientos médicos esperando que la muerte llegue de manera natural, y la eutanasia activa, el procedimiento llevado a cabo por un médico que pone fin, de manera directa, a la vida de una persona.

El derecho a morir dignamente se posiciona dentro de la categoría de derechos emergentes. Es un derecho nuevo, reconocido de manera doméstica a través de un

\footnotetext{
El Laboratorio de Derechos Económicos, Sociales y Culturales es una plataforma de derechos humanos que pone los derechos humanos en acción de forma creativa, innovadora y útil para las personas, las familias, las organizaciones, las empresas y el Estado. A través de la estrategia \#TomaElControl, provee información y recursos para que las personas conozcan, tomen decisiones anticipadas y recursos para hacer efectivo el derecho a morir dignamente en Colombia; igualmente, litiga casos de alto impacto para avanzar y consolidar dicho derecho humano. Más información en: https://www.desclab.com/tomaelcontrol
} 
proceso de activismo judicial (Correa-Montoya, 2020) con un limitado proceso de movilización social y de litigio estratégico (Correa-Montoya, 2011).

\subsection{Derechos humanos emergentes, algunas ideas de contexto}

La Declaración Universal de los Derechos Humanos Emergentes ${ }^{2}$ (Instituto de Derechos Humanos de Cataluña [IDHC], 2009) establece que todos los seres humanos, ciudadanos o no de un Estado en particular, tenemos más derechos que aquellos que se encuentran, en un momento dado, positivados en los ordenamientos jurídicos domésticos o internacionales. Hay que reconocer que hay derechos humanos que emergen de diferente manera, con distintos actores y para dar respuesta a diferentes demandas sociales. Este reconocimiento deriva de entender estas garantías universales y constitucionales, no como una apropiación estática espaciotemporal, sino como un catálogo ético sobre el cuál transformar el presente y, como lo establece Julios-Campuzano (2002, p. 213), cimentar un futuro más esperanzador.

La pregunta por los derechos humanos emergentes, como lo es el derecho a morir dignamente, es una pregunta por nuevos derechos humanos, por nuevas categorías jurídicas que impliquen una reinvención y reinterpretación de los valores que inspiran, representan y materializan el sistema universal y los sistemas regionales de derechos humanos. Los nuevos derechos pueden emerger en diferentes foros y de diferentes maneras. Su emergencia implica una pregunta por la naturaleza y las dimensiones emancipadoras, críticas y reivindicativas de los derechos humanos (Julios-Campuzano, 2002, p. 204), la no aceptación del catálogo de derechos como un producto terminado que puede dar respuesta acertada a todas las necesidades antiguas o novedosas frente a las cuales nos encontramos.

Todo lo contrario, es una pregunta por las necesidades invisibles, por las poblaciones oprimidas y sumergidas, así como las actuales transformaciones sociales que dan pie a la emergencia de nuevos derechos: la pobreza, la corrupción, el subdesarrollo, el cambio climático, la amenaza nuclear y biológica, las innovaciones tecnológicas, las migraciones y el desplazamiento de población, la discriminación, la globalización y transnacionalización, la longevidad de la población, entre otros. Hay que reconocer que el mundo en que vivimos es significativamente diferente del mundo en que han surgido los derechos humanos desde la Revolución Francesa, las constituciones liberales, la Declaración Universal de Derechos Humanos. En nuestros días, se abre la posibilidad de discutir la necesidad y justificación de nuevos derechos.

Es sabido que los derechos humanos son categorías históricas, surgidas generacionalmente, a través de un proceso dilatado y arduo, no carente de

2 La Declaración Universal de los Derechos Humanos Emergentes no es un instrumento jurídicamente vinculante. Es un documento aspiracional y de agenda que fija un horizonte de sentido para la emergencia de nuevos derechos que den respuestas a las necesidades actuales en las que los derechos humanos positivados son incapaces de dar una respuesta efectiva. 
polémicas, disputas y enfrentamientos, cuyos hitos son auténticas rupturas institucionales. [...] Nada permite suponer que este proceso histórico de decantación de los derechos humanos haya concluido, entre otras cosas porque las libertades evolucionan pari passu con las necesidades humanas y éstas [sic] van adquiriendo perfiles propios en cada momento histórico. [...] Nunca, a lo largo de la historia, fue ésta [sic] una materia pacífica: la conquista de los derechos humanos está jalonada por un rosario de estragos, persecuciones, revueltas, luchas y revoluciones. (Julios-Campuzano, 2002, p. 205)

Pero esa emergencia no debe limitarse al estudio de los mecanismos formales de creación de derechos. Como lo establece la Declaración Universal de los Derechos Humanos Emergentes, la emergencia de nuevos derechos supera las formalidades, va más allá del debate monopolizado por los agentes estatales en el derecho internacional de los derechos humanos y reconoce, de otro lado, que otros actores como la sociedad civil y los actores domésticos puedan catalizar dicha emergencia (IDHC, 2009, p. 42). La Declaración misma busca contribuir, desde la sociedad civil, a diseñar un nuevo horizonte de derechos que sirva de orientación a los movimientos sociales, las políticas públicas y las agendas de quienes gobiernan en el ámbito local (IDHC, 2009, p. 40).

La emergencia del derecho a morir dignamente en Colombia es un proceso que ha tenido como actor central al poder judicial, a la Corte Constitucional. Es ella, a través de su labor activista y de creadora de derechos, la que ha liderado el proceso - muchas veces en solitario, con un poder legislativo casi ausente y un poder ejecutivo muchas veces limitado- para cumplir las órdenes judiciales que se le imparten. Aun así, el avance en el reconocimiento del derecho a morir dignamente en el ordenamiento constitucional colombiano es significativamente mayor al que se puede encontrar en algunos instrumentos internacionales con diversa fuerza vinculante.

El derecho a morir dignamente en Colombia ha logrado mayores avances que los alcanzados, aún de manera tímida, por instrumentos de agenda internacional y por instrumentos regionales de derechos humanos. A continuación se abordarán dos instrumentos que se refieren, de diferentes maneras, al derecho a morir dignamente.

La Declaración Universal de los Derechos Humanos Emergentes define el derecho a la muerte digna como el derecho a no prolongar artificialmente la vida y a que se respete la voluntad de la persona expresada en un testamento vital o en un documento similar (IDHC, 2009, art. 1(7)). Este abordaje no se refiere al acceso a cuidados paliativos ni a la eutanasia activa, es decir, a la ayuda efectiva para poner fin a la vida de la persona. El derecho a morir dignamente se circunscribe a su faceta relacionada con la eutanasia pasiva, es decir, a la no prolongación de la vida de manera innecesaria, pero en la que la muerte llega de manera natural. Esta aproximación al derecho a morir dignamente es altamente limitada cuando se comparara con los avances constitucionales que han tenido lugar en Colombia. 
El Sistema Interamericano de Derechos Humanos, la reciente Convención sobre los Derechos de las Personas Mayores (Organización de los Estados Americanos [OEA], 2015) incorpora el acceso a cuidados paliativos dentro del derecho a la salud. Esta convención menciona tangencialmente la eutanasia pasiva en el marco del derecho a la vida, pero no reconoce la muerte digna como un derecho humano autónomo.

La Convención incluye una definición de cuidados paliativos como

la atención y cuidado activo, integral e interdisciplinario de pacientes cuya enfermedad no responde a un tratamiento curativo o sufren dolores evitables, a fin de mejorar su calidad de vida hasta el fin de sus días [.. . A Afirman la vida y consideran la muerte como un proceso normal; no la aceleran ni retrasan. (OEA, 2015, art. 2)

Esta última acotación, en lo que a la relación de los cuidados paliativos con la muerte se refiere, fija los contornos y limitaciones de la muerte digna en este tratado internacional.

En el marco del reconocimiento del derecho a la salud de las personas mayores, la Convención establece que, dentro de las políticas intersectoriales de salud que deban adoptarse, deben incluirse los cuidados paliativos (OEA, 2015, art. 19), pero no establece nada más sobre el fin de la vida. Sin embargo, más allá del tradicional derecho a la salud, que en este tratado se reconoce a un grupo invisible —el de las personas mayores - consta un derecho emergente para este mismo grupo poblacional y para la población en general. El derecho a brindar consentimiento libre e informado en el ámbito de la salud (OEA, 2015, art. 11) no es un derecho completamente nuevo porque sus contenidos, en general, se han reconocido en el marco del derecho a la salud, la autonomía y la integridad física; pero en este tratado emerge como una categoría independiente.

Particularmente se refiere al derecho de las personas mayores a aceptar, negarse a recibir o interrumpir voluntariamente tratamientos médicos o quirúrgicos, incluida la posibilidad de manifestar la voluntad de manera anticipada respecto de diversas intervenciones en salud (OEA, 2015, art. 11). Este derecho emergente podrá, en el futuro, catalizar decisiones más profundas sobre el fin de la vida como un derecho internacionalmente protegido.

Finalmente, la muerte es abordada en este tratado de manera tangencial y atada al derecho a la vida. Hay una mención a la vida digna hasta el final de sus días, sin que esta expresión lleve directamente a hablar de un derecho a la muerte digna, pero sí a conservar la dignidad hasta el fin de la vida. De allí deriva la obligación de los estados de tomar medidas

para que las instituciones públicas y privadas ofrezcan a la persona mayor un acceso no discriminatorio a cuidados integrales, incluidos los cuidados paliativos, eviten el aislamiento y manejen apropiadamente los problemas relacionados con el miedo a la muerte de los enfermos terminales, el dolor, y eviten el sufrimiento 
innecesario y las intervenciones fútiles e inútiles, de conformidad con el derecho de la persona mayor a expresar el consentimiento informado. (OEA, 2015, art. 6)

Cuando se comparan los tímidos avances en materia internacional, bien sea a través de documentos de agenda internacional o de tratados internacionales de derechos humanos, el estado actual del derecho a morir dignamente en Colombia constituye un avance significativo, pues da cuenta de la emergencia de este derecho como un derecho fundamental constitucionalmente reconocido, cuyos contenidos y alcances se detallarán a lo largo del texto.

La emergencia del derecho se ha acompañado de un aumento en el acceso y ejercicio del mismo por parte de los ciudadanos. Con corte al 8 de mayo de 2020 se habían realizado noventa y cuatro procedimientos en todo el país desde 2015, año desde el cual se tienen registros (Ministerio de Salud y Protección Social [MSPS], 2020). El 2019 fue el año con más eutanasias activas practicadas, en total se desarrollaron treinta y cinco procedimientos. Es un número alto si se compara con el 2015, primer año de aplicación de la Resolución 1216 (2015), en el que se desarrollaron cuatro procedimientos, es decir, la práctica de la eutanasia activa se ha multiplicado por nueve en cuatro años.

Mujeres y hombres han accedido a la muerte digna a través de la eutanasia activa en casi iguales proporciones. Nada indica que un sexo sea más abierto y dispuesto a querer acceder a la muerte digna. Desde 2015, cuarenta y ocho hombres y cuarenta y seis mujeres se han practicado este procedimiento. Bogotá y Antioquia (Medellín) son los lugares en donde mayor cantidad de personas accedieron a la eutanasia activa. Desde 2015 se reportaron cuarenta y un casos en Bogotá y treinta y tres en Antioquia (principalmente en Medellín), es decir, el 78,7 \% de todas las eutanasias practicadas de manera legal en Colombia. Les siguen Risaralda y Valle del Cauca con nueve casos cada uno. Finalmente, están Caldas y Bolívar cada uno con un caso (MSPS, 2020).

No se han practicado eutanasias activas legalmente en niños ni en adolescentes, las cuales son legalmente posibles desde 2018 (Resolución 825, 2018). El 89 \% de los procedimientos de eutanasia activa fueron practicados a personas que tenían un diagnóstico relativo al cáncer (MSPS, 2020). El Ministerio de Salud y Protección Social no reporta otros diagnósticos debido a que, dado el número de procedimientos realizados, sería posible individualizar los casos.

\subsection{La muerte digna: un derecho fundamental de aplicación inmediata que puede ser protegido judicialmente}

El derecho a morir dignamente es, de acuerdo con los avances jurisprudenciales colombianos, un derecho fundamental complejo, autónomo, independiente pero relacionado con otros derechos constitucionales. No es un componente de la autonomía personal ni del libre desarrollo de la personalidad, tampoco es una parte del derecho a la vida. Se trata de un derecho complejo porque su aplicabilidad depende de circunstancias 
particulares y restrictivas que deben verificarse previamente para no incurrir en delitos (Sentencia T-970, 2014); todos los ciudadanos tienen derecho a la muerte digna, pero no todos pueden ejercerlo en cualquier momento ni de cualquier modo.

Esta naturaleza no fue clara desde el momento mismo de la emergencia del derecho. Todo lo contrario, en la Sentencia C-239 (1997) no hay una mención directa a la naturaleza del derecho fundamental a morir dignamente, solo se indica en esa decisión que "el derecho fundamental a vivir en forma digna implica entonces el derecho a morir dignamente" (Sentencia C-239, 1997). Realmente lo que sucede en el año 1997 es la despenalización de la eutanasia activa bajo el rótulo penal del homicidio por piedad, cuando se configuran unos requisitos específicos que dan sustancia el contenido normativo del derecho a morir dignamente.

Es hasta la Sentencia T-970 (2014) que emerge, con completa claridad, el derecho fundamental a morir dignamente, es decir, un derecho de rango constitucional que, entre otras características, no necesita del desarrollo legislativo para ser efectivo y puede ser garantizado a través de la acción de tutela. En dicha decisión, la Corte justifica la naturaleza de derecho fundamenta por tres razones. La primera razón tiene que ver con el derecho a morir dignamente como fundamento la dignidad humana:

para esta Corte no cabe duda que el derecho a morir dignamente tiene la categoría de fundamental. Y ello es así por varias razones. Siguiendo sus razonamientos, esta Corporación ha señalado que un derecho fundamental busca garantizar la dignidad del ser humano. Es decir, para que una garantía pueda ser considerada como fundamental, debe tener una estrecha relación con la dignidad como valor, principio y derecho de nuestro ordenamiento constitucional. En el caso de la muerte digna, la Sala de Revisión, al igual que la Sala Plena en la Sentencia C-239 de 1997, considera que su principal propósito es permitir que la vida no consista en la subsistencia vital de una persona, sino que vaya mucho más allá. Esos aspectos adicionales son propios de un sujeto dotado de dignidad que como agente moral, puede llevar a cabo su proyecto de vida. Cuando ello no sucede, las personas no viven con dignidad. Mucho más si padece de una enfermedad que le provoca intenso sufrimiento al paciente. En estos casos, ¿quién si no es la propia persona la que debe decidir cuál debería ser el futuro de su vida? ¿Por qué obligar a alguien a vivir, en contra de su voluntad, si las personas como sujetos derechos pueden disponer ellos mismos de su propia vida? (Sentencia T-970, 2014)

La segunda razón se relaciona con un consenso sobre la existencia del derecho. Particularmente, dicho consenso se basó en las dos sentencias anteriores sobre la materia y sobre las órdenes dadas al legislativo para regular el derecho a morir dignamente. La tercera razón obedece a que se trata de una garantía susceptible de ser traducida en un derecho subjetivo, en el cual los actores activos y pasivos, así como el contenido mínimo, estén claros. Estos elementos habían sido explícitos en el precedente judicial desde el año 1997. A partir de la sentencia hito del 2014, todas las sentencias posteriores se han referido al derecho a morir dignamente como un 
derecho fundamental y, a partir de los casos concretos que abordaron, profundizaron su protección por la vía judicial y ampliaron los contornos de su núcleo esencial.

Así, emergió el derecho a morir dignamente como un derecho fundamental reconocido dentro del ordenamiento jurídico colombiano como producto de la agencia de las élites judiciales a lo largo del tiempo. Algunos casos aislados, sin un trasfondo o estrategia de movilización social respaldado por la sociedad civil, llegaron al conocimiento de la más alta instancia constitucional colombiana, quien moldeó el derecho e insertó en la órbita constitucional (Correa-Montoya, 2020).

\section{GRAVITAR EN EL ORDENAMIENTO JURÍDICO CONSTITUCIONAL. EL DERECHO A MORIR DIGNAMENTE EN EL CONTÍNUUM DE DERECHOS}

Los derechos humanos, más allá de discusiones históricas y de diferentes formas de clasificación, forman con un contínuum (Abramovich, 2006, p. 8), un conjunto de derechos universales, indivisibles, interdependientes e interrelacionados (Asamblea General de Naciones Unidas, 1993). La emergencia del derecho a morir dignamente en la jurisprudencia constitucional colombiana se ha apoyado en su relación, interacción y presión sobre otros derechos constitucional e internacionalmente protegidos para encontrar y afirmar su lugar. En el proceso en que emerge un nuevo derecho, el juez constitucional, en su función creadora de derecho, ha tenido especial cuidado al articular este proceso creativo con otros derechos ya existentes en el ordenamiento internacional y constitucional para llenarlo de contenido, coherencia y articularlo lógicamente, de forma que su emergencia no fuera un proceso caprichoso o autoritario por parte de las élites judiciales.

El juez constitucional, de esta manera, ha reconocido diferentes tensiones, relaciones y presiones del derecho a morir dignamente con otros derechos como la vida, la dignidad humana, la autonomía y el libre desarrollo de la personalidad; el derecho a la salud, la protección en contra de la tortura, los tratos crueles, inhumanos y degradantes; y la libertad de conciencia de los profesionales de la medicina. Posicionar el derecho a morir dignamente en el contínuum de derechos ha fundado su contenido y relevancia constitucional, ha hecho menos frágil su emergente existencia, la cual ha estado, como se relata, en riesgo.

\subsection{Tensión con el derecho a la vida: un derecho más allá de una vida biológica que nadie está obligado a vivir}

En el proceso de emergencia del derecho a morir dignamente, la Corte Constitucional colombiana debió abordar y resolver la aparente tensión que existe entre este y el derecho a la vida. La Corte zanjó esta tensión al reafirmar que la protección del derecho a la vida ocupa un lugar de primera importancia en la Constitución Política de 1991. Es un derecho constitucionalmente protegido por el artículo 11 de la Constitución Política (1991). Su protección y aseguramiento es un valor del ordenamiento constitucional 
presente en el preámbulo; es una obligación en cabeza de las autoridades públicas; es también un deber ciudadano. No solo se debe actuar de manera humanitaria ante situaciones que pongan en riesgo la vida de los demás (Constitución Política, 1991, art. 95(2)), sino que también es un deber que lleva al cuidado de la salud propia (Constitución Política, 1991, art. 49) y, por tanto, de la vida propia (Sentencia C-239, 1997). Al no dejar de lado ni obviar la especial importancia del derecho a la vida y no entender la muerte digna en tensión con la vida, el juez creador de derecho le allanó un lugar relativamente seguro en el cual fundarse.

No obstante, desde una perspectiva pluralista, la Corte también ha reconocido que el derecho a la vida no es absoluto, ni siquiera ante el hecho de que la Constitución Política de 1991 establezca que el derecho a la vida es inviolable, ni tampoco por la especial y detallada protección que la Constitución le brinda. Al no ser absoluto, como no lo es ningún derecho, no existe el deber absoluto de vivir ni de preservar la vida en cualquier circunstancia y a toda costa. En casos específicos, como en el caso del derecho a morir dignamente, el derecho a la vida y el correlativo deber de protegerla deben ceder.

En segundo lugar, la Corte reconoció que, frente a la vida, pueden encontrarse diferentes aproximaciones. Algunas la entienden como un bien sagrado sobre el que las personas tienen un margen de decisión restringida. Otras, por el contrario, la entienden como algo valioso, pero no absoluto, íntimamente relacionada con la autonomía y el proyecto de vida personal. La Corte fijó la manera en que los casos sobre muerte digna deben abordarse: en la Sentencia C-239 (1997) estableció que deben abordarse desde una perspectiva pluralista en la que se dividan las cuestiones jurídicas de aquellas morales; en la que quien quiera entender la vida como algo sagrado puede hacerlo, pero no puede imponérselo como deber a los demás.

Esta precisión resultó estratégica en este proceso de emergencia del derecho a morir dignamente. Que la tensión se resolviera desde las primeras sentencias que abordaron el caso, particularmente desde la Sentencia C-239 (1997), logró que la discusión y la muy común confusión entre derecho y moral religiosa, quedara, en principio, zanjada. Se materializó, así, el efecto de reestructuración de marco del que hablan Rodríguez-Garavito y Rodríguez-Franco (2015, p. 26) cuando conceptualizan los efectos del activismo judicial, bajo el cual las decisiones fijan y establecen el enfoque desde donde deben decidirse situaciones similares o entenderse el problema público que abordan. Así, la Corte se ha visto limitada a volver a caer en la trampa de la moral religiosa y de la sacralidad de la vida como algo que se impone por unas mayorías genéricas y etéreas a personas específicas que desean tomar decisiones personales sobre el fin de la vida. Esto no quiere decir que las discusiones estén exentas de este tipo de riesgos. Sin embargo, este aporte de la Sentencia C-239 (1997) brindó un nivel de blindaje importante, aún ante magistrados típicamente identificados como 
conservadores e inclusive religiosos, quienes encuentran más difícil hacer pasar sus posiciones personales y morales por posiciones jurídicamente valiosas.

La discusión sobre la coexistencia del derecho a la vida y el derecho a la muerte digna, como derechos correlacionados, no ha sido pacífica. En la aclaración de voto de la Sentencia T-544 (2017), la magistrada disidente argumentó que:

en cierto modo el reconocimiento simultáneo del derecho a la vida y el derecho a ejecutar o autorizar acciones directamente contrarias a la vida parece lógicamente imposible, o por lo menos no parece congruente con la exigencia de tomarse los derechos en serio. Reconocer simultáneamente el derecho a la vida y la legitimidad de acciones directamente occisivas es tan absurdo como reconocer el derecho a la propiedad y al hurto, o el derecho al buen nombre y a la injuria.

Sus ideas no fueron de recibo en la decisión de la sala y no fueron efectivas para entorpecer la emergencia y posicionamiento del derecho a morir dignamente.

\subsection{La relación con la dignidad humana, el libre desarrollo de la personalidad y la vida digna}

La ponderación del derecho a la vida con el principio constitucional de la dignidad humana ha resultado ser uno de los argumentos jurídicos más poderosos en el proceso de emergencia del derecho a morir dignamente, pues le ha permitido a la Corte Constitucional colombiana aparatarse de una protección absoluta del derecho a la vida y dar cabida a las decisiones sobre el fin de la misma.

Desde la Sentencia T-090 (1996), la Corte reconoció el poder del principio constitucional del respeto por la dignidad humana para evitar la homogenización y masificación de las personas y, por tanto, la protección constitucional de toda traza de originalidad y peculiaridad de las personas:

Si la persona es en sí misma un fin, la búsqueda y el logro incesantes de su destino conforman su razón de ser y a ellas por fuerza acompaña, en cada instante, una inextirpable singularidad de la que se nutre el yo social, la cual expresa un interés y una necesidad radicales del sujeto que no pueden quedar desprotegidas por el derecho a riesgo de convertirlo en cosa. (Sentencia T-090, 1996)

El principio de la dignidad humana encuentra, como se establece en la Sentencia C-239 (1997), su máxima expresión en el libre desarrollo de la personalidad (Constitución Política, 1991, art. 16) y en el derecho a la autonomía. Solo cuando estos derechos constitucionales se protegen, la dignidad humana se materializa y evita que las personas sean cosificadas e instrumentalizadas más allá de sus propios deseos y decisiones.

Desde el primer caso relativo al derecho a morir dignamente (Sentencia T-493, 1993), la Corte Constitucional colombiana reconoció la relación directa del derecho al libre desarrollo de la personalidad en el proceso de emergencia. En la Sentencia T-493 (1993), la Corte estableció que 
el derecho al libre desarrollo de la personalidad consiste en la libertad general, que en aras de su plena realización humana, tiene toda persona para actuar o no actuar según su arbitrio, es decir, para adoptar la forma y desarrollo de vida que más se ajuste a sus ideas, sentimientos, tendencias y aspiraciones, sin más restricciones que las que imponen los derechos ajenos y el ordenamiento jurídico

Este libre desarrollo de la personalidad incluye la posibilidad de prescindir, suspender y negarse a ser sometido a tratamientos médicos, aun si esa decisión lleva a la muerte.

Luego, en la Sentencia C-239 (1997), la Corte estableció que

La Constitución se inspira en la consideración de la persona como un sujeto moral, capaz de asumir en forma responsable y autónoma las decisiones sobre los asuntos que en primer término a él incumben, debiendo el Estado limitarse a imponerle deberes, en principio, en función de los otros sujetos morales con quienes está avocado a convivir, y por tanto, si la manera en que los individuos ven la muerte refleja sus propias convicciones, ellos no pueden ser forzados a continuar viviendo cuando, por las circunstancias extremas en que se encuentran, no lo estiman deseable ni compatible con su propia dignidad, con el argumento inadmisible de que una mayoría lo juzga un imperativo religioso o moral.

Pero la protección de la dignidad humana no solo riñe o entra en tensión con el derecho a la vida, también lo irradia y lo permea. Entender y proteger el derecho a la vida desde este principio lleva a concluir, como lo hace la Corte, que la vida no puede verse simplemente como algo sagrado o como una realidad biológica que tiene que ser vivida de cualquier modo,

hasta el punto de desconocer la situación real en la que se encuentra el individuo y su posición frente el valor de la vida para sí [... .] el derecho a la vida no puede reducirse a la mera subsistencia, sino que implica el vivir adecuadamente en condiciones de dignidad. (Sentencia C-239, 1997)

El derecho fundamental a vivir en forma digna implica, entonces, como lo ha establecido la Corte en las sentencias C-239 (1997), T-970 (2014) y T-423 (2017), la existencia del derecho a morir dignamente. De esta manera, en el proceso de emergencia del derecho a morir dignamente, la Corte Constitucional colombiana no solo fijó la perspectiva desde la cual se entiende y protege el derecho a la vida, sino que lo irradia con el principio de la dignidad humana y lo permea con el derecho al libre desarrollo de la personalidad para crear una relación directa entre el derecho a la vida digna y el derecho a morir dignamente, no como dos categorías antagónicas, sino hermanas e inclusive sucesivas para una vida digna y plena debe suceder una muerte en igualdad de condiciones.

Pero la discusión sobre la dignidad humana tampoco ha sido pacífica. La aclaración de voto de la magistrada disidente en la Sentencia T-544 (2017) permite avizorar las 
posiciones más conservadoras que quisieran obstaculizar, impedir o retrotraer el proceso de surgimiento y consolidación del derecho.

El primer argumento de oposición es que la vida, como un hecho biológico, no puede dejar de ser digna, pues la dignidad de la misma deriva del hecho de tenerla, de estar vivos:

La sentencia fundadora de la línea que hoy se recoge parece partir de la base de que existen condiciones en las que la vida deja de ser digna. Esta afirmación resulta incompatible con el modelo de Estado Social de Derecho, si se entiende como significativa de que la vida, en sí misma considerada, ha dejado de ser digna. En efecto, la vida no es una simple operación entre muchas, sino que consiste en el ser mismo del viviente. Perder la vida, para un viviente es perder su propio ser. (Sentencia T-544, 2017)

Y, en segundo lugar, se argumenta que considerar que una vida es indigna significa considerar que tiene un menor valor, así ello se disfrace tras el manto del derecho a la autonomía y al libre desarrollo de la personalidad: "Al enfermo terminal se le "autoriza" a morir, no porque se respete su autonomía (como algunas veces se intenta presentar) sino porque de alguna manera, su vida se considera "menos" por el ordenamiento" (Sentencia T-544, 2017). Los argumentos en contra desconocen el rol fundamental que el consentimiento de la persona juega en el ejercicio del derecho y pretenden retrotraer profundas discusiones sobre la dignidad humana y el libre desarrollo de la personalidad en el fin de la vida.

\subsection{La presión con la protección en contra de la tortura, tratos crueles, inhumanos y degradantes}

La Constitución Política (1991) colombiana dispone que "nadie será sometido a desaparición forzada, a torturas ni a tratos o penas crueles, inhumanos o degradantes" (art. 12). En el proceso de emergencia del derecho a morir dignamente, la Corte Constitucional ha presionado este derecho para consolidar el lugar del último como derecho innominado en el contínuum de derechos constitucionalmente protegidos. La presión sobre esta protección, a lo largo de los años de desarrollo jurisprudencial, ha adoptado tres manifestaciones: la primera se refiere a los efectos sobre la vida de las personas; la segunda, a las barreras administrativas, burocráticas y técnicas impuestas por el sistema de salud; y la tercera, a la falta de reglamentación del derecho que genera vacíos y justifica la inacción de las entidades en el sector salud.

Desde los inicios del proceso de emergencia, la Corte Constitucional colombiana abordó la primera manifestación de esta presión sobre la protección en contra de la tortura. En la Sentencia C-239 (1997) indicó que no hay "nada tan cruel como obligar a una persona a subsistir en medio de padecimientos oprobiosos, en nombre de creencias ajenas, así una inmensa mayoría de la población las estime intangibles" y continuó estableciendo que 
el derecho fundamental a vivir en forma digna implica entonces el derecho a morir dignamente, pues condenar a una persona a prolongar por un tiempo escaso su existencia, cuando no lo desea y padece profundas aflicciones, equivale no sólo [sic] a un trato cruel e inhumano, prohibido por la Carta (CP art.12), sino a una anulación de su dignidad y de su autonomía como sujeto moral. La persona quedaría reducida a un instrumento para la preservación de la vida como valor abstracto. (Sentencia T-423, 2017)

A través de la Sentencia T-423 (2017), la Corte Constitucional colombiana abordó un caso en que los operadores del sistema de salud impusieron barreras al ejercicio del derecho a morir dignamente, a pesar de las peticiones y la reglamentación clara con la cual se contaba en ese momento. Se presenta así la segunda manifestación de la presión sobre la protección en contra de la tortura. Las órdenes de la sentencia en mención fueron más allá y buscaron reparar simbólicamente el daño ocasionado a la persona y a su familia, a quien se le practicó el procedimiento eutanásico, pero vulnerando derechos e imponiendo un trato degradante e inhumano al prolongar innecesariamente el sufrimiento en el que la persona se veía inmersa. La Corte, entonces, estableció una serie de órdenes orientadas a mejorar y solucionar las fallas burocráticas y reforzó los mecanismos de supervisión y monitoreo. En este sentido, no solo exigió que se registraran los procedimientos realizados, sino también las solicitudes formuladas.

La tercera manifestación de la presión del derecho a la muerte digna sobre la protección en contra de la tortura es aquella relativa a la falta de reglamentación del primero que genera vacíos y justifica la inacción de las entidades en el sector salud, que derivan en tratos crueles, inhumanos y degradantes al prolongar innecesariamente la vida. En la Sentencia T-544 (2017), la Corte Constitucional estableció que

el derecho a la muerte digna no solo comprende el acto médico de eutanasia sino que para su efectividad abarca también el trámite oportuno y expedito de las solicitudes elevadas por los pacientes dirigidas a obtener la garantía del derecho en mención.

En este caso, los padres de un menor de edad con discapacidad solicitaron al asegurador en salud que practicara el procedimiento eutanásico. Sin embargo, la falta de regulación sobre el acceso de los niños, niñas y adolescentes (NNA) al derecho a morir dignamente fue la excusa para no garantizar este derecho en el tiempo razonable, y ello significó la prolongación de una existencia mediada por el dolor y el sufrimiento. La Corte estableció así que

la falta de regulación del derecho a la muerte digna de los NNA impidió que se determinara si concurrían los requisitos para la realización de la eutanasia en el adolescente y la consecuente prolongación de su aflicción, la cual no tiene justificación alguna y corresponde a un trato cruel e inhumano que no respetó su dignidad, ni consideró su situación como sujeto de especial protección constitucional. (Sentencia T-544, 2017) 


\section{El vacío normativo detonó}

la intervención urgente del juez constitucional para evitar que otros NNA sean víctimas de un trato cruel e inhumano derivado de la negación de su derecho a morir dignamente. En efecto, el valor inconmensurable de cada vida humana y la dignidad que le es propia refuerza la necesidad de evitar que un caso como este se repita en el futuro. (Sentencia T-544, 2017)

Por orden de la Corte, el Ministerio de Salud y Protección Social reglamentó la materia a través de la Resolución 825 (2018). La discusión en relación con la presión sobre la protección en contra de la tortura y su relación con el derecho a morir dignamente tampoco ha sido pacífica. La magistrada disidente en la Sentencia T-544 (2017) argumentó que al

analizar el argumento de que la dignidad, si bien nunca se pierde, exige "eximir" al enfermo del "deber" de soportar dolores extremos. Ciertamente, la dignidad conlleva una exigencia de optimización de las condiciones vitales, así como el derecho efectivo a reestablecer la salud, mitigar el dolor e incluso la renuncia al procedimiento médico. En este sentido, se ha de aceptar la existencia de un derecho a no soportar dolores extremos, cuando sea jurídica y fácticamente posible evitarlos, que se manifiesta, por una parte, en el derecho al tratamiento curativo y paliativo y, por otra, en el derecho a no ser sometido a tratamientos no consentidos. Tal derecho no puede entenderse extensivo, sin embargo, al acto de eutanasia, cuyo objeto inmediato es la terminación de la vida, así sea para evitar el dolor.

De esta manera, la protección en contra del dolor, los tratos crueles y la tortura para la minoría judicial, no fue suficiente para justificar la existencia constitucional del derecho a morir dignamente. En este sentido, se admite que solo se puede llegar hasta un punto de alivio, pero la muerte debe llegar de manera natural.

\subsection{Garantizar el derecho a la salud y su relación con el derecho a morir dignamente}

La relación con el derecho a la salud, reconocido en el artículo 49 de la Constitución Política colombiana (1991), ha sido usada por el juez constitucional en el proceso de emergencia del derecho a morir dignamente en, por lo menos, dos sentidos: uno para irradiar su contenido, otro para limitar su uso desmedido y abusivo. La relación con el derecho a la salud surgió en un momento avanzado del proceso de emergencia del derecho a morir dignamente, cuando la Corte de vio abocada, luego del 2014, a resolver casos concretos de personas que encontraban distintas dificultades para garantizar su derecho y, en otros casos, no cumplían estrictamente con los requisitos fijados en el precedente judicial como se detalló en la primera parte.

En primer lugar, la relación del derecho a la salud con el derecho a morir dignamente ha sido usada para irradiar su contenido, los requisitos que deben cumplirse y la forma como puede materializarse. Uno de los requisitos para exigir el derecho a morir dignamente es tener una enfermedad en estado terminal debidamente diagnosticada 
por el médico tratante. Este hecho hace que, previo a hacer efectivo este derecho, el derecho a la salud también tenga que ser protegido efectivamente, por lo menos en lo que a recibir un diagnóstico efectivo se refiere.

La Corte estableció que

el derecho fundamental a la salud incluye la posibilidad de contar con un diagnóstico efectivo (Corte Constitucional, Sentencia T-132 de 2016). Tal faceta implica (i) la valoración oportuna sobre las dolencias que tenga el paciente, (ii) determinar la enfermedad que padece, para luego (iii) establecer el procedimiento médico específico que se deba seguir para lograr el restablecimiento de la salud de la persona. (Sentencia T-132, 2016)

Pero el diagnóstico efectivo no se refiere a un derecho genérico a saber qué dolencia aflige a la persona. La Corte ha establecido en detalle a qué se refiere en la Sentencia T-717 (2009): i) la práctica de las pruebas, exámenes y estudios médicos necesarios; ii) la calificación igualmente oportuna y completa de ellos por parte de la autoridad médica correspondiente a la especialidad y, para el caso de la muerte digna, del estado terminal ; y iii) la prescripción por el personal médico tratante del procedimiento, medicamento o implemento que se considere pertinente para su tratamiento.

La relación con el derecho a la salud no se ha quedado en la posibilidad de obtener un diagnóstico efectivo como requisito para acceder al derecho a morir dignamente. La relación con el derecho a la salud ha irradiado las diferentes opciones que tienen las personas para materializar el derecho. El acceso a cuidados paliativos, como primera opción, requiere de un sistema de salud que provea este tipo de servicios de manera oportuna y de calidad (Sentencia T-423, 2017); de otra manera, la garantía del derecho a morir dignamente resulta inocua o nominal. Pero la práctica de la eutanasia, sea pasiva o activa, requiere también de la plena garantía del derecho a la salud. En su versión pasiva, la persona debe acceder a los servicios de salud para poder desistir de ellos, rechazarlos o suspender su aplicación (Sentencia T-493, 1993); en su versión activa, el proceso eutanásico debe solicitarse ante los prestadores y aseguradores del sistema de salud. Son ellos quienes deben constituir el comité encargado de estudiar y llegar a una decisión sobre el caso, así como determinar el profesional de la medicina concreto que llevará a cabo el procedimiento (Sentencia C-239, 1997; Sentencia T-970, 2014).

En segundo lugar, la Corte Constitucional colombiana ha usado la relación con el derecho a la salud para evitar abusos en el uso del derecho a morir dignamente en casos en los que se cumplen los estrictos requisitos establecidos en la jurisprudencia. En tres casos específicos la Corte detalló la mencionada relación. En la Sentencia T-132 (2016) la Corte negó a una persona recluida en un centro penitenciario su solicitud para poner fin a su existencia, dado que, a pesar de tener un estado de salud delicado, no cumplía con el requisito de la enfermedad terminal que se exige. La Corte identificó en este caso las difíciles barreras para el acceso al derecho a la salud y ordena resolverlas. 
En la Sentencia T-322 (2017), la Corte estudió el caso de una persona mayor quien había solicitado el procedimiento eutanásico y había interpuesto una acción de tutela de manera verbal para que se le garantizara su derecho a morir dignamente. En este caso, la Corte estableció el deber estricto de constatación que tiene el juez de tutela cuando frente a él se presentan este tipo de casos. Este deber le exige, por la naturaleza de la petición, profundizar en el caso y en otras vulneraciones de derechos que pudieran tener lugar. Por último, en la Sentencia T-060 (2020), la Corte negó una tutela por considerar que la persona, diagnosticada con alzhéimer, no tenía una enfermedad terminal y no había manifestado anticipadamente su consentimiento ante el procedimiento.

La protección del derecho a morir dignamente debe estar acompañada de la garantía del derecho a la salud, de modo que la motivación para poner fin a la existencia no derive de barreras y dificultades para acceder a tratamientos, medicamentos y prestaciones de salud, sino de la decisión libre de poner fin a la vida porque esta ha dejado de ser digna.

\subsection{La tensión con la libertad de conciencia de los profesionales de la medicina}

Finalmente, en el proceso de emergencia del derecho a morir dignamente, la Corte Constitucional colombiana ha abordado la tensión con la libertad de conciencia de los profesionales de la medicina, quienes son los únicos autorizados para llevar a cabo el procedimiento eutanásico.

La tensión existe porque, de un lado, Sentencia C-239 (1997) estableció que uno de los requisitos para que la eutanasia activa fuera legal y no constituyera la comisión de un delito, es que un profesional de la medicina preste la ayuda efectiva para poner fin a la vida. Pero, por otro lado, dichos profesionales de la medicina están cobijados por la libertad de conciencia consagrada en la Constitución Política (1991) que establece que "nadie será molestado por razón de sus convicciones o creencias ni compelido a revelarlas ni obligado a actuar contra su conciencia" (art. 18). Como producto de esta garantía constitucional, surge la objeción de conciencia como mecanismo constitucional para negarse, legítimamente, a practicar la eutanasia.

La jurisprudencia constitucional resolvió está tensión al imponer al prestador de servicios de salud la obligación de contar con un grupo médico que, de manera anticipada, no fuera objetor de conciencia y que, en caso de presentarse la objeción de conciencia por parte del profesional asignado para llevar a cabo el procedimiento, el mismo prestador de servicios de salud provea, en máximo veinticuatro horas, otro profesional de la medicina que no fuere objetor (Sentencia T-970, 2014). Posteriormente, en la Sentencia T-423 (2017), la Corte reafirmó la obligación de los profesionales de la medicina de ejercer su libertad de conciencia de manera escrita y motivada, de forma que dicha garantía constitucional no se convirtiera en una barrera más que las 
personas debían enfrentar al momento de hacer efectivo su derecho a morir dignamente (Sentencia T-423, 2017).

Si bien la Corte ha resuelto la tensión balanceando los derechos de las partes involucradas sin compeler a los profesionales de la medicina a actuar en contra de su voluntad y conciencia, tanto la Resolución 1216 (2015) como la Resolución 825 (2018) del Ministerio de Salud y Protección Social fueron más allá. Estas reglamentaciones eliminan la posibilidad de la objeción de conciencia institucional, es decir, son los profesionales de la medicina, en su calidad de ciudadanos y sujetos de derechos constitucionales quienes gozan de libertad de conciencia, no las instituciones hospitalarias ni las aseguradoras en salud, quienes prestan un servicio público y no pueden objetar el desarrollo de estos procedimientos (MSPS, 2015, art. 18).

La discusión sobre la objeción de conciencia, particularmente en lo que se refiere a las instituciones prestadoras de servicios de salud, tampoco ha sido pacífica. En la aclaración de voto de la magistrada disidente en la Sentencia T-544 (2017) argumentó que:

la Sentencia T-970 de 2014 convirtió la eutanasia en una obligación absoluta para todas las entidades prestadoras de salud. Esto último generó que el Ministerio de Salud, a través de la Resolución 1216 de 2015, impusiera a todas las IPS la obligación de tener personal médico no objetor, sin considerar la situación de las instituciones que prestan el servicio a la salud a la luz de un ideario ético religioso, las cuales se encuentran amparadas por el literal a) del artículo 14 de la Ley 133 de 1994, legislación de carácter estatutario por desarrollar el artículo 19 de la Constitución Política.

No obstante, la posibilidad de que instituciones hospitalarias pudieran profesar unas creencias específicas que en algunos momentos las llevaran a negar la garantía del derecho a morir dignamente, no ha sido acogida por las mayorías en la sede judicial.

En el proceso de emergencia y consolidación del derecho a morir dignamente, la jurisprudencia constitucional ha abordado las relaciones, tensiones y presiones que este derecho tiene y genera con otros derechos constitucionalmente protegidos. Abordarlas ha servido para resolver cuestiones que pudieran entorpecer su emergencia y consolidación, pero también para sustentar la discusión sobre la muerte digna en una discusión más amplia de garantía de derechos constitucionales en el fin de la vida.

\section{DE QUÉ HABLAMOS CUANDO HABLAMOS DEL DERECHO A MORIR DIGNAMENTE. REFLEXIONES SOBRE EL NÚCLEO ESENCIAL}

Una vez analizada la forma en que el derecho a morir dignamente se ha afincado en el contínuum de derechos constitucionales, en la tercera sección se abordan las opciones que brinda a los ciudadanos para hacerlo efectivo, así como los requisitos que deben cumplirse. El derecho a morir dignamente es un derecho fundamental 
que tienen las personas en Colombia. Sin embargo, cuando la garantía a través de la eutanasia activa es de carácter restrictivo y excepcional, es necesario verificar previamente unos requisitos estrictos antes de hacerlo efectivo. De lo contrario, una aplicación indiscriminada de esta potestad podría significar una desprotección de otros derechos constitucionales, entre ellos la vida.

\subsection{Tres opciones para acceder a la muerte digna}

Con frecuencia, el derecho a la muerte digna se asimila a la eutanasia activa, pero esta opción no agota su contenido esencial. El derecho incluye, además de la eutanasia activa, la eutanasia pasiva y el acceso a los cuidados paliativos como opciones para materializarse. Se trata de un asunto de opciones que se le presentan al ciudadano para decidir y tomar el control del fin de la vida, sin verse coaccionado a decidir por una $u$ otras.

Las diferentes decisiones judiciales se han referido conceptualmente a la eutanasia y a los cuidados paliativos como parte del razonamiento judicial, pero es la Sentencia T-721 (2017) la que mejor lo sintetiza al establecer que

el derecho fundamental a morir con dignidad tiene múltiples dimensiones y no es unidimensional, como hasta ahora se ha concebido, haciendo énfasis en la muerte anticipada (sic) o el procedimiento denominado «eutanasia», pues se trata de un conjunto de facultades que permiten a una persona ejercer su autonomía y tener control sobre el proceso de su muerte e imponer a terceros límites respecto a las decisiones que se tomen en el marco del cuidado de la salud.

La primera es, de esta manera, la eutanasia activa, regulada en la Resolución 1216 (2015) para los mayores de edad y en la Resolución 825 (2018) para los niños, niñas y adolescentes. Esta opción está disponible para personas que tienen una enfermedad terminal debidamente diagnosticada, la cual les causa intensos dolores y sufrimientos físicos y psicológicos que les hacen considera que su vida ha dejado de ser digna; manifiestan su voluntad de manera directa o sustituta para que un profesional de la medicina les preste una ayuda efectiva para morir.

La segunda opción es la eutanasia pasiva, también conocida como la limitación del esfuerzo terapéutico o la readecuación de las medidas asistenciales. En estos casos, las personas con enfermedades terminales, crónicas, degenerativas, irreversibles o con alto impacto en la calidad de vida, desisten por sí mismas o a través terceros, anticipadamente o cuando ya están en curso, de tratamientos médicos innecesarios que no cumplen con los principios de proporcionalidad terapéutica o que no sirven para mejorar el estado de salud o la calidad de vida. De esta manera, se da paso a que el proceso de la enfermedad hacia la muerte siga su curso natural, sin que sea el profesional de la medicina quien la causa (Ley 1733, 2014, art. 1). 
La tercera opción es el acceso a cuidados paliativos, los cuales integran un conjunto diverso de prestaciones médicas y asistenciales orientadas a mejorar su calidad respecto del paciente y de su familia a través de un tratamiento integral del dolor, el alivio del sufrimiento y otros síntomas, teniendo en cuenta aspectos psicopatológicos, físicos, emocionales, sociales y espirituales (Ley 1733, 2014, art. 4). Dado que los cuidados paliativos son, principalmente, unos procedimientos médicos, los pacientes pueden rechazarlo. Su acceso no impide que posteriormente puedan optar por la eutanasia pasiva o activa o por ambas.

Por otro lado, el suicidio asistido no hace parte de las opciones que brinda el derecho a morir dignamente en Colombia. Por el contrario, es un delito tipificado en el Código Penal colombiano (Ley 599, 2000, art. 107). La diferencia fundamental con la eutanasia activa es que en esta el profesional de la medicina despliega la acción que genera la muerte, mientras que en el caso del suicidio asistido el profesional de la medicina o cualquier otra persona induce o presta asistencia para que sea la persona misma quien termine con su propia vida.

El derecho a morir dignamente implica que la autonomía y el libre desarrollo de la personalidad se garanticen en el fin de la vida, esto es, que la vida corresponda, en sus últimos momentos, con los deseos y decisiones de las personas. Implica, además, que estas no se vean constreñidas a vivir el fin de su vida en contra de sus decisiones y deseos. Esto incluye la decisión legítima de quien salva su alma a través del sufrimiento esperando a que el fin sea dispuesto por su idea de dios. Incluye esperar la muerte de manera natural con el acceso a los cuidados paliativos necesarios para aliviar o sobrellevar el dolor y el sufrimiento. También incluye la posibilidad de desistir de tratamientos y procedimientos que resultan innecesarios y que inducen el sufrimiento mientras se espera el desenlace final. En general, las anteriores opciones no generan tanta discusión personal, familiar ni jurídica, en tanto no alteran el curso natural de la vida ni inducen directamente la muerte.

Es, finalmente, la eutanasia activa la que genera los debates a nivel personal, familiar y jurídico y es en torno a ella que la emergencia del derecho resulta una novedad, no solo en ámbito constitucional colombiano, sino en el ámbito internacional y comparado. Es, entonces, a esta opción del derecho a morir dignamente a la que se refieren los avances constitucionales que siguen.

\subsection{La enfermedad terminal y la pregunta sobre cuán próximo debe ser el pronóstico fatal}

El primer requisito para acceder a la eutanasia activa como opción para garantizar el derecho a morir dignamente es que la persona, sea mayor o menor de edad, tenga una enfermedad en estado terminal debidamente diagnosticada. El razonamiento judicial tras este requisito es que las personas que enfrentan una enfermedad terminal saben que no pueden ser curados y, por ende, no optan entre la muerte y muchos años de 
vida, sino entre morir en las condiciones que escogen o morir poco tiempo después en circunstancias dolorosas que juzga y considera indignas (Sentencia C-239, 1997).

Posteriormente, la Ley 1733 (2014) introdujo la definición de enfermo en fase terminal que será replicada en las resoluciones 1216 (2015) y 825 (2018). La Ley 1733 (2014) define el concepto como

todo aquel que es portador de una enfermedad o condición patológica grave, que haya sido diagnosticada en forma precisa por un médico experto, que demuestre un carácter progresivo e irreversible, con pronóstico fatal próximo o en plazo relativamente breve, que no sea susceptible de un tratamiento curativo y de eficacia comprobada, que permita modificar el pronóstico de muerte próxima; o cuando los recursos terapéuticos utilizados con fines curativos han dejado de ser eficaces. (art. 2)

Ni la jurisprudencia constitucional, ni la Ley 1733 (2014), ni la Resolución 1216 (2015) precisan qué significa tener un pronóstico fatal próximo o en un plazo relativamente breve. El protocolo para la aplicación del procedimiento de eutanasia en Colombia es el documento oficial que fija, sin valor de norma jurídica, el tiempo máximo de seis meses que se considera próximo, así como las pruebas estandarizadas que se recomiendan para determinarlo. El protocolo lo define así:

enfermo terminal es aquel paciente con una enfermedad medicamente comprobada avanzada, progresiva, incontrolable que se caracteriza por la ausencia de posibilidades razonables de respuesta al tratamiento, por la generación de sufrimiento físico-psíquico a pesar de haber recibido el mejor tratamiento disponible y cuyo pronóstico de vida es inferior a 6 meses. (MSPS, 2015, p. 13)

Posteriormente, la Resolución 825 (2018) establecerá el tiempo de seis meses al nivel reglamentario, al indicarlo expresamente en la definición de niño, niña o adolescente con enfermedad en estado terminal (art. 2(2.4)).

Si bien la jurisprudencia constitucional ha considerado que este requisito es objetivo porque es afirmado médicamente, establecer el pronóstico de vida de una persona es un ejercicio que está lejos de ser objetivo, estandarizado, preciso, cierto y de amplio consenso y evidencia científica de alta calidad. Por el contrario, es un ejercicio de pronóstico en función de lo que a otros les ocurrió en el pasado. Se dispone de varias herramientas y metodologías cuyos resultados y confiabilidad, como el mismo Ministerio de Salud y Protección Social lo establece, varían significativamente. Hay un mayor desarrollo en el pronóstico de enfermedades oncológicas (MSPS, 2015, p.13) y un menor desarrollo en otro tipo de enfermedades, principalmente aquellas que encajan en la definición de enfermedad crónica, degenerativa e irreversible de alto impacto en la calidad de vida (Ley 1733, 2014, art. 3).

Los casos más recientes sobre el derecho a morir dignamente han abordado solicitudes de personas que, a pesar de tener diferentes tipos de diagnósticos mé- 
dicos, no tenían una enfermedad en estado terminal. En estos casos, también había duda sobre si se contaba con la manifestación del consentimiento, la Corte se enfocó principalmente en este último asunto con las sentencias T-721 (2017) y T-060 (2020). En los años por venir, la Corte enfrentará el reto de abordar un caso de muerte digna en el que la persona enfrente una enfermedad crónica, degenerativa e irreversible de alto impacto en la calidad de vida, en el que el pronóstico de vida sea mayor a seis meses y en el que la argumentación constitucional gire en torno al deterioro en la calidad de vida y no en torno al consentimiento.

\subsection{Considerar que la vida ha dejado de ser digna como producto del sufrimiento}

No basta tener una enfermedad en estado terminal debidamente diagnosticada para acceder a la eutanasia activa como mecanismo para hacer efectivo el derecho a morir dignamente. Se requiere, en segundo lugar, que dicha enfermedad genere intenso sufrimiento, físico o psíquico, que lleve a la persona a considerar que su vida y existencia han dejado de ser dignas.

La Corte ha reconocido, desde la misma Sentencia C-239 (1997), que este elemento es puramente subjetivo, es decir, responde a la esfera más íntima de la persona y que, aún cuando existan herramientas para determinar o calificar el dolor, es la persona misma quien mejor puede juzgar su dolor y sufrimiento y, ejercer así, su derecho a la autonomía y al libre desarrollo de la personalidad para decidir las condiciones en que su vida debe llegar al fin. Existe, como se indicó en la Sentencia T-970 (2014), una prevalencia de la autonomía de la persona sobre los criterios médicos:

una vez se tenga certeza de que se trata de una patología terminal, adquiere relevancia el elemento subjetivo, consistente en el dolor que cause sufrimiento intenso al paciente. Aunque se pueda establecer médicamente que una enfermedad implica mucho dolor (aspecto objetivo), limitar esa certeza a un concepto médico choca con la idea misma de autonomía y libertad de las personas. Nadie más que el propio paciente sabe que algo le causa un sufrimiento de tal envergadura que se hace incompatible con su idea de dignidad. Los dolores pueden ser médicamente de muchas clases y la falta de acuerdo médico puede llevar a la vulneración de los derechos del paciente. Aunque el papel del médico en estos procedimientos es indispensable, no por ello es absoluto. De esta manera, será la voluntad del paciente la que determine qué tan indigno es el sufrimiento causado, aunado a los exámenes médicos. No pueden los médicos oponerse a la voluntad del paciente cuando quiera que objetiva y subjetivamente su voluntad se encuentra depurada. Existe una prevalencia de la autonomía del enfermo.

El dolor y el sufrimiento que puede llegar a padecer una persona, el cual cataliza la aplicación del derecho a morir dignamente a través de la eutanasia activa, debe entrar en estricta relación con la dignidad humana. Esto quiere decir que el acceso a la eutanasia activa no se sigue inmediatamente del dolor o sufrimiento que pueda padecer una persona, sino de la valoración subjetiva y personal que ella hace de su situación. 
Esto hace que la decisión de poner fin a la vida sea una decisión personalísima que se relaciona con lo que la persona juzga para sí misma como deseable, con su idea de vida digna, pero también con su situación familiar, sus convicciones personales, inclusive religiosas.

Recientes sentencias han tenido que abordar la tensión entre esta decisión personalísima y la intervención de otras personas en la valoración de ese dolor o sufrimiento. Esta situación también se relaciona con el requisito del consentimiento que se desarrollará más adelante. En las sentencias T-544 (2017), T-721 (2017) y T-060 (2020), la Corte se enfrentó a situaciones en las que la valoración del sufrimiento y de la vida digna las llevaban a cabo otras personas, en los dos primeros casos los padres y en el último una hija. Adicionalmente, por la situación de salud y de discapacidad, no era posible recurrir a la persona para recabar su posición o valoración de la dignidad de su vida. En el caso de la T-060 (2020), aún antes del deterioro producido por la enfermedad crónica, degenerativa e irreversible, la mujer a quien se le iba a practicar el procedimiento no había dado luces ni asomo alguno de decisión anticipada. En todos los casos subsistía la duda sobre la valoración personal sobre el sufrimiento insoportable y el deterioro de la vida digna, dudas que se mezclaban con el cansancio de los cuidadores y un supuesto cansancio vital.

A la vez, ni la jurisprudencia constitucional ni la reglamentación derivada han calificado el tipo de dolor que debe experimentar la persona. Pero basta con que ese dolor, sea físico o sicológico, sea calificado o valorado por la persona que lo experimenta como intenso, insoportable e incompatible con su idea de vida digna. Por ello, este requisito aplica a cualquier tipo de dolor o sufrimiento que experimente la persona y, por tanto, no se restringe al dolor o sufrimiento físico. A través de la Sentencia T-423 (2017), la Corte estableció que el derecho a la muerte digna por medio de la eutanasia activa "es aplicable no solamente a los padecimientos de dolores corporales, sino análogamente a todos aquellos eventos que en razón de una enfermedad, se menoscaben la salud e integridad física o mental de la persona". Sin embargo, a la fecha, la Corte no ha tenido un caso en donde la faceta de dolor sicológico o mental, atado a su impacto sobre la calidad de vida y la vida digna, lleven a una persona a solicitar, por sí misma, la garantía de la muerte digna a través de la eutanasia activa.

\subsection{Manifestar el consentimiento}

Ejercer el derecho a morir dignamente, en particular a través de la eutanasia activa, es una decisión personalísima en la que cada persona juzga sus condiciones de vida, el tiempo del que dispone y su idea de dignidad. Para ejercer este derecho se requiere manifestar el consentimiento, pero no basta cualquier tipo de manifestación. A lo largo del proceso de emergencia del derecho, la jurisprudencia constitucional ha evaluado 
las características que debe satisfacer, los momentos en que puede tener lugar y la posibilidad de ser sustituido.

Desde los inicios de la emergencia del derecho a morir dignamente, en la Sentencia C-239 (1997) se fijaron las cuatro características que deben satisfacer el consentimiento para considerarse suficiente y válido para acceder a la eutanasia activa:

el consentimiento del sujeto pasivo debe ser libre, manifestado inequívocamente por una persona con capacidad de comprender la situación en que se encuentra. Es decir, el consentimiento implica que la persona posee información seria y fiable acerca de su enfermedad y de las opciones terapéuticas y su pronóstico, y cuenta con la capacidad intelectual suficiente para tomar la decisión. (Sentencia C-239, 1997)

Posteriormente, la Corte detallaría el significado de cada una de estas características. Libre "implica que no existan presiones de terceros sobre su decisión. Lo determinante es que el móvil de la decisión sea la genuina voluntad del paciente de poner fin al intenso dolor que padece" (Sentencia T-970, 2014). Informado significa que la persona y su familia cuenten con toda la información objetiva y necesaria para tomar la decisión, de forma que nos sea apresurada o sesgada (Sentencia T-970, 2014); que quien toma la decisión sea capaz, no solo en términos jurídicos, de comprender la decisión que está tomando y los efectos irreversibles que de ella derivan (Sentencia T-322, 2017); que no sea el producto de momentos de consciencia alterados, críticos o depresivos (Sentencia T-970, 2014). Finalmente, inequívoco significa que la decisión sea clara, que no deje lugar a duda alguna, que sea consciente y sostenida en el tiempo (Sentencia T-970, 2014).

La jurisprudencia constitucional ha reconocido, además, que la manifestación del consentimiento puede tener lugar en diferentes momentos. Puede ser posterior al momento en que una persona se entera de su diagnóstico médico, y esa situación cataliza la decisión personalísima sobre la muerte digna. No obstante, este momento para manifestar el consentimiento puede no funcionar en todos los casos porque la enfermedad o la situación de salud, como en los casos de emergencia o accidente, puede no dar el tiempo suficiente o puede deteriorar, más o menos rápido, la situación de salud, la calidad de vida o la capacidad de tomar una decisión libre, informada e inequívoca.

Por ello, la jurisprudencia ha reconocido que la manifestación del consentimiento puede ser previa o anticipada a conocer el diagnóstico o a estar en una situación en la que la calidad de vida se deteriore y se haga indigna. A lo largo del proceso de emergencia del derecho a morir dignamente, particularmente la sociedad civil ha desarrollado diferentes documentos y herramientas que permiten a las personas manifestar su voluntad de manera anticipada. 
Los documentos de voluntad anticipada fueron abordados tangencialmente por la Ley 1733 de 2014 (Ley 1733, 2014, art. 5(4)) y reglamentados inicialmente por la Resolución 1051 (2016). La reglamentación inicial se refería solo a las decisiones anticipadas sobre la eutanasia pasiva y no abordaba directamente la posibilidad de decidir anticipadamente sobre la eutanasia activa. No obstante, dichos documentos comenzaron a ser utilizados para manifestar la voluntad anticipada en los casos de eutanasia activa en la medida que la reglamentación no lo prohibía y, por tanto, podía ser usada de manera analógica. El artículo 4 de la Resolución 1051 (2016) estableció los contenidos mínimos del documento y la manera como debía ser formalizado. Para esa época, el documento debía ser presentado siempre ante notario público, inclusive si se suscribía con testigos o mediante audio o video. Esta restricción generó que su formalización ante testigos o por medio de otros mecanismos diferentes al escrito resultaran poco prácticos para la toma de decisiones (Resolución 1051, 2016, art. 6).

Posteriormente, en 2018, el Ministerio de Salud y Protección Social actualizó la reglamentación a través de la Resolución 2665 (2018). En ella se sigue sin mencionar explícitamente la posibilidad de usar este tipo de documentos en casos de eutanasia activa, a pesar de que el artículo 15 de la Resolución 1216 (2015) había establecido que este tipo de documentos eran válidos para manifestar el consentimiento en casos de eutanasia activa. No obstante, esta resolución corrige varios aspectos: primero, no solo restringe la formalización del documento ante notario público; segundo, permite que el documento sea suscrito y formalizado a través de testigos, y esos testigos pueden ser familiares de la persona que toma la decisión; tercero, permite formalizarlo ante el médico tratante y que este lo incorpore en la historia clínica; cuarto, permite que la manifestación sea hecha en audio y video, y esta será válida si cumple con los contenidos mínimos sin necesidad de formalizarla ante notario como lo exigía la anterior reglamentación.

La jurisprudencia, desde la Sentencia T-970 (2014), estableció que el consentimiento también podía ser sustituto o sustituido. Esta figura ocurre "cuando la persona que sufre de una enfermedad terminal se encuentra en imposibilidad fáctica para manifestar su consentimiento. En esos casos y en aras de no prolongar su sufrimiento, la familia, podrá sustituir su consentimiento. En esos eventos, se llevará a cabo el mismo procedimiento establecido en el párrafo anterior, pero el comité interdisciplinario deberá ser más estricto en el cumplimiento de los requisitos" (Sentencia T-970, 2014). La figura del consentimiento sustituto no ha sido pacífica en el proceso de emergencia del proceso del derecho a morir dignamente.

La Resolución 1216 (2015), que reglamentó el procedimiento y las responsabilidades de los actores del sistema de salud en lo que a la eutanasia activa se refiere, fusionó los conceptos de consentimiento sustituto con el de consentimiento anticipado. En este sentido, estableció que 
en caso de que la persona mayor de edad se encuentre en incapacidad legal o bajo la existencia de circunstancias que le impidan manifestar su voluntad, dicha solicitud podrá ser presentada por quienes estén legitimados para dar el consentimiento sustituto, siempre y cuando la voluntad del paciente haya sido expresada previamente mediante un documento de voluntad anticipada o testamento vital y requiriéndose, por parte de los familiares, que igualmente se deje constancia escrita de tal voluntad. (Resolución 1216, 2015, art. 15)

Posteriormente, las sentencias T-721 (2017) y T-060 (2020) tuvieron que volver sobre dicho asunto para establecer judicialmente que, al haberse efectuado esta asimilación, en efecto se eliminó la figura del consentimiento sustituto establecido en la Sentencia T-970 (2014). En este sentido, se hizo nugatorio el derecho a morir dignamente de las personas que, eventualmente, se llegaren a encontrar en incapacidad para decidir. Desde 2017 la Corte ordenó al Ministerio de Salud y Protección Social reglamentar la materia y, en 2020, dicha orden judicial no había sido cumplida.

Finalmente, la jurisprudencia ha establecido que el consentimiento puede ser formal o informal; se entiende formal por la vía escrita e informal por la vía verbal (Corte Sentencia T-970, 2014). La reglamentación, como ya se ha establecido, ha intentado brindar diferentes opciones y mecanismos para manifestar la voluntad de manera válida y anticipada con más o menos requisitos. De esta manera, intenta lograr un punto medio entre la formalidad exigida por el tipo de decisión que se toma y las facilidades necesarias para que, al momento de decidir, la persona encuentre las menores barreras que impidan la garantía de su derecho a morir dignamente.

\section{CONCLUSIONES}

El derecho a morir dignamente ha emergido como un derecho fundamental, autónomo y multidimensional en el ordenamiento jurídico colombiano. A lo largo de su proceso de emergencia, llevado a cabo a través de un proceso de activismo judicial, se ha afincado en la órbita de otros derechos constitucionales. Esta estrategia argumentativa, desarrollada por los operadores judiciales, le ha dado coherencia y pertenencia y ha encontrado su lugar en una discusión constitucional más amplia.

Como derecho multidimensional, el derecho a morir dignamente no se materializa únicamente a través de la eutanasia activa, sino que brinda, como se han detallado, otras opciones. Sin embargo, la eutanasia activa es la que mayor discusión y oposición encuentra, no solo en el seno de las élites judiciales, sino en la opinión pública y, al emerger ella como una opción para ejercer el derecho a la muerte digna, resulta especialmente interesante e innovadora.

El proceso de emergencia del derecho a morir dignamente y la consolidación de su núcleo esencial no es un proceso terminado. En los años venideros, la Corte, el poder legislativo y el ejecutivo se enfrentarán a retos no resueltos. La discusión gira sobre la enfermedad terminal y cuán próxima debe estar la muerte para acceder a la 
eutanasia activa; el consentimiento sustituto para llevar a cabo la eutanasia activa, los requisitos específicos para que opere y la necesaria y correlativa protección a la vida que impida abusos y prácticas eugenésicas. Este último reto tendrá que considerar, particularmente, las tensiones éticas en la aplicación del procedimiento a personas mayores y a personas con discapacidad que no encajan, y nunca han encajado, en la visión y expectativa capacitista (Goodley, 2014) del derecho a morir dignamente. Esto se debe a que este derecho se sustenta en la idea de la persona autodeterminada y plenamente capaz de tomar la decisión de desprenderse de la vida como un acto personalísimo por excelencia.

Finalmente, la Corte, pero también el legislativo, deberán avocarse a las discusiones sobre la legalidad y no tipicidad del suicidio asistido en el marco de la naturaleza multidimensional del derecho a morir dignamente.

\section{REFERENCIAS}

Abramovich, V. (2006). Una aproximación al enfoque de derechos en las estrategias y políticas de desarrollo. Revista de la Cepal, 88. https://www.cepal.org/es/publicaciones/11102-aproximacion-alenfoque-derechos-estrategias-politicas-desarrollo

Asamblea General de Naciones Unidas (1993, 12 de julio). Declaración y Programa de Acción de Viena. https://www.ohchr.org/Documents/Events/OHCHR20/VDPA_booklet_Spanish.pdf

Asamblea Nacional Constituyente de Colombia (1991). Constitución Política de 1991. http://www. secretariasenado.gov.co/senado/basedoc/constitucion_politica_1991.html

Congreso de la República de Colombia (2000). Ley 599 del 2000. http://www.secretariasenado.gov.co/ senado/basedoc/ley_0599_2000.html

Congreso de la República de Colombia (2014). Ley 1733 de 2014. http://www.secretariasenado.gov.co/ senado/basedoc/ley_1733_2014.html

Correa-Montoya, L. (2011). Litigio de alto impacto: estrategias alternativas para enseñar y ejercer el Derecho. Opinión Jurídica, 7(14), 149-162. https://revistas.udem.edu.co/index.php/opinion/ article/view/161

Correa-Montoya, L. (2020). Muerte digna en Colombia. Activismo judicial, cambio social y discusiones constitucionales sobre un derecho emergente. DescLAB. https://www.desclab.com/monitor/monitor05

Corte Constitucional colombiana (1993). Sentencia T-493/93 (Antonio Barrera Carbonell, M. P). https:// www.corteconstitucional.gov.co/relatoria/1993/T-493-93.htm

Corte Constitucional colombiana (1996). Sentencia T-090/1996 (Eduardo Cifuentes Muñoz, M. P.). https://www.corteconstitucional.gov.co/relatoria/1996/t-090-96.htm

Corte Constitucional colombiana (1997). Sentencia C-239/97 (Carlos Gaviria Díaz, M. P). https://www. corteconstitucional.gov.co/relatoria/1997/c-239-97.htm

Corte Constitucional colombiana (2009). Sentencia T-717/09 (Gabriel Eduardo Mendoza Martelo, M. P). https://www.corteconstitucional.gov.co/relatoria/2009/T-717-09.htm

Corte Constitucional colombiana (2014). Sentencia T-970/14 (Luis Ernesto Vargas Silva, M. P). https:// www.corteconstitucional.gov.co/relatoria/2014/t-970-14.htm 
Corte Constitucional colombiana (2016). Sentencia T-132/16 (Luis Ernesto Vargas Silva, M. P). https:// www.corteconstitucional.gov.co/relatoria/2016/t-132-16.htm

Corte Constitucional colombiana (2017). Sentencia T-322/17 (Aquiles Arrieta Gómez, M. P). https:// www.corteconstitucional.gov.co/relatoria/2017/t-322-17.htm

Corte Constitucional colombiana (2017). Sentencia T-423/17 (Humberto Escrucería Mayolo, M. P). https://www.corteconstitucional.gov.co/relatoria/2017/t-423-17.htm

Corte Constitucional colombiana (2017). Sentencia T-544/17 (Gloria Stella Ortiz Delgado, M. P). https:// www.corteconstitucional.gov.co/relatoria/2017/t-544-17.htm

Corte Constitucional colombiana (2017). Sentencia T-721/17 (Antonio José Lizarazo Ocampo, M. P). https://www.corteconstitucional.gov.co/relatoria/2017/t-721 17.htm

Corte Constitucional colombiana (2020). Sentencia T-060/2020 (Alberto Rojas Ríos, M. P). https:// www.corteconstitucional.gov.co/Relatoria/2020/T-060-20.htm

Goodley, D. (2014). Disability Studies. Theorising disablism and ableism. Routledge.

Instituto de Derechos Humanos de Cataluña, IDH (2009). Declaración Universal de los Derechos Humanos Emergentes. IDHC. https://www.idhc.org/es/investigacion/publicaciones/derechos-humanosemergentes/declaracion-universal-de-derechos-humanos-emergentes.php

Julios-Campuzano, A. (2002). La globalización y la crisis paradigmática de los derechos humanos. Revista de Estudios Políticos (nueva época), 116, abril-junio. https://dialnet.unirioja.es/servlet/ articulo?codigo $=249223$

Ministerio de Salud y Protección Social (2015). Resolución 1216 de 2015. https://www.minsalud.gov.co/ Normatividad_Nuevo/Resoluci\%C3\%B3n\%201216\%20de\%202015.pdf

Ministerio de Salud y Protección Social (2018). Resolución 825 de 2018. https://www.minsalud.gov.co/ sites/rid/Lists/BibliotecaDigital/RIDE/DE/DIJ/resolucion-0825-de-2018.pdf

Ministerio de Salud y Protección Social (2015). Protocolo para la aplicación del procedimiento de eutanasia en Colombia. Universidad de Antioquia, la Universidad Nacional de Colombia y la Fundación Meditech. https://www.minsalud.gov.co/sites/rid/Lists/BibliotecaDigital/RIDE/DE/CA/Protocolo-aplicacionprocedimiento-eutanasia-colombia.pdf

Ministerio de Salud y Protección Social (2016). Resolución 1051 de 2016. https://www.minsalud.gov.co/ Normatividad_Nuevo/Resoluci\%C3\%B3n\%201051\%20de\%202016.pdf

Ministerio de Salud y Protección Social (2020, 8 de mayo). Reporte de eutanasias activas practicadas.

Organización de los Estados Americanos. (2015). Convención Interamericana sobre la protección de derechos humanos de las personas mayores, A-70, 06/15/2015. http://www.oas.org/es/sla/ddi/tratados multilaterales_interamericanos_a-70_derechos_humanos_personas_mayores.asp

Rodríguez-Garavito, César y Rodríguez-Franco, Diana. (2015). El juicio a la exclusión. El impacto de los tribunales sobre los derechos sociales en el sur global. Siglo XXI Editores. https://www.dejusticia.org/wpcontent/uploads/2017/04/fi_name_recurso_758.pdf 